\title{
Infants of Hypothyroid Mothers at Risk of Developing Hypothyroidism: A Cross-sectional Study in Qassim Region of Saudi Arabia
}

\author{
Mariam S. Alharbi* (D) \\ Internal Medicine Department, College of Medicine, Qassim University, Buraydah P.O. Box 1162, 52571, Kingdom of Saudi Arabia
}

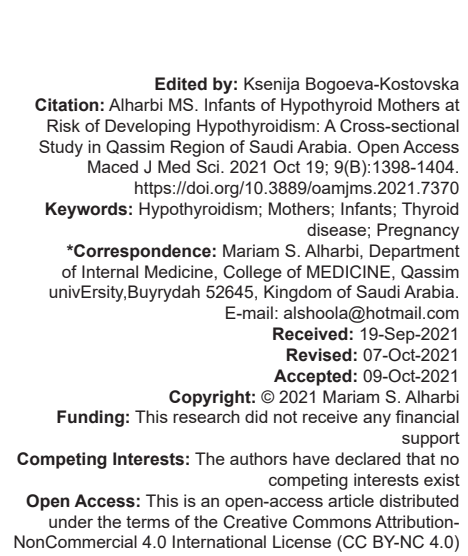

\section{Introduction}

Pregnancy increases the demand of the maternal thyroid gland since it should adjust to the numerous physiological transformations happening in the body during pregnancy. The thyroid gland has to release satisfactory amount of thyroid hormone so as to encounter the requirements of mother as well as fetus as up till the $12^{\text {th }}$ week of gestation, the fetus is entirely reliant on mother for its supply of thyroid hormones [1]. The fetal thyroid gland initiates thyroid hormones production at the end of the $1^{\text {st }}$ trimester but there is still need of a satisfactory maternal supply of iodine [2]. However, to meet this increased demand, the thyroid gland experiences numerous structural as well as functional modifications, induced by several physiological mechanisms in the mother's body.

Some of the functional transformations that usually occurs during pregnancy include: (i) a rise in the production of total triiodothyronine (T3) and thyroxine (T4) owing to stimulatory influences of beta-human chorionic gonadotropin ( $\beta$-hCG) and human chorionic thyrotropin, (ii) a decline in the production of thyroidstimulating hormone (TSH) from the anterior pituitary gland because of the high concentration of $\beta$-hCG levels during the first trimester (which can elicit subclinical hyperthyroidism) and (iii) a 2-3 times upsurge in concentrations of thyroid hormone-binding globulin (TBG). This happens because of several times increase in the TBG half-life by estrogen-stimulated sialylation of TBG and an increase in hepatic production of TBG. This modification additionally augments the total serum thyroid hormone levels as most of the thyroid hormone ( $80 \%$ of T3 and $68 \%$ of T4) circulating in the blood is bound to TBG [3], [4].

There are two types of hypothyroidism, i.e., overt or clinical hypothyroidism and other is subclinical hypothyroidism. Overt hypothyroidism is elevated serum TSH and declined FT4, or, TSH $>10 \mathrm{mIU} / \mathrm{L}$ with FT4 within the normal range. Subclinical hypothyroidism is serum TSH above the reference range, and FT4 within the normal range [5]. The prevalence of overt and subclinical hypothyroidism in pregnancy is estimated at $0.3 \%$ to $0.5 \%$ and $2 \%$ to $3 \%$ respectively [6]. Hypothyroid symptoms may be non-specific and similar to those experienced in 
pregnancy, such as fatigue, constipation, dry skin, cold intolerance, and mental clouding [7]. A descriptive cross-sectional study was conducted in Suez Canal university hospitals of Ismailia, Egypt with an aim to investigate the functional status of the thyroid gland during pregnancy by means of conducting thyroid function test (TFT). It was observed that most of the pregnant women had normal thyroid functions, while subclinical hypothyroidism was the most prevalent disorder followed by clinical hypothyroidism and isolated hypothyroxinemia [8]. Clinical hypothyroidism is linked with pregnancy complications such as abortions, pre-eclampsia, anemia, placental abnormalities, and postpartum hemorrhage [9]. The infants born to hypothyroid mothers may have complications for example premature birth, low birth weight, intrauterine growth restriction and increased neonatal respiratory distress, congenital hypothyroidism $(\mathrm{CH})$, and impaired cognitive function [4].

A prospective observational study Gupta et al. [10] determined the prevalence of clinical and subclinical hypothyroidism and also explored the fetal and maternal complications associated with hypothyroidism. It was revealed that the prevalence of thyroid disorder was $6.22 \%$, subclinical hypothyroidism, and clinical hypothyroidism being $3.77 \%$ and $2.45 \%$, respectively. In the subclinical group and clinical group, the common complications were; preeclampsia followed by preterm labor; first trimester abortions, and oligohydramnios. Moreover, it was noticed that subclinical hypothyroidism was more frequent and unidentified leading to the poor obstetrical outcome and fetal complications such as low birth weight, prematurity, and intrauterine growth restriction. There was higher incidence of cesarean deliveries in both groups more in clinical hypothyroid cases.

A study Männistö et al. [11] explored pregnancy complications associated with common and uncommon thyroid diseases. It was observed that primary hypothyroidism was associated with increased odds of maternal outcomes, for example., preeclampsia, superimposed preeclampsia, gestational diabetes, preterm birth, induction, cesarean section, and intensive care unit (ICU) admission. latrogenic hypothyroidism was associated with increased odds of placental abruption, breech presentation, and cesarean section after spontaneous labor. Therefore, screening of pregnant women is important to avoid such complications that can even negatively impact fetus and newborns. A retrospective study Fallatah et al. [12] conducted in a tertiary care hospital of Jeddah, Saudi Arabia. It was concluded that obese pregnant women with hypothyroidism are more prone to adverse maternal and neonatal outcomes than normal population. It was revealed that preterm labor, gestational diabetes mellitus (DM), and urinary tract infections were significantly associated with abnormal TSH levels. Moreover, the study added that hypothyroidism during pregnancy is associated with great maternal and neonatal risk, such as gestational DM, preterm labor, admission to neonatal ICU and neonatal death. Similarly, a crosssectional study Al Shanqeeti et al. [13] conducted in Riyadh, Saudi Arabia revealed that the prevalence of subclinical hypothyroidism in pregnant women was $13 \%$. Pregnant women who were randomly screened using a survey were three times more likely to have subclinical hypothyroidism compared to pregnant women who were screened based on their physician's judgment.

A study Hussein [14] investigated the prevalence of thyroid dysfunction in pregnant women in a tertiary care hospital of Jeddah, Saudi Arabia. The prevalence of hypothyroidism was $40.25 \%$ and hyperthyroidism $0.6 \%$ using the cutoff TSH level based on the guidelines of the American Thyroid Association for the diagnosis and management of thyroid disease during pregnancy. It was indicated that hypothyroidism is more common in Saudi pregnant women in the western province of Saudi Arabia. Given the negative maternal and fetal outcomes associated with maternal thyroid dysfunction, it is crucial to diagnose abnormal thyroid status in early pregnancy to avoid complications for mothers and newborns. Therefore, it is suggested that maternal thyroid dysfunction screening shall be done as early as possible, particularly in a country like Saudi Arabia where there is high prevalence of undiagnosed thyroid dysfunction.

A study conducted in Italy reported that they repeatedly screened infants born to hypothyroid mothers during the $1^{\text {st }}$ month of life with TFTs. It was noted that 3 out of 129 infants were given thyroxine therapy based on mild TSH elevation (range 10.5$13.6 \mathrm{IU} / \mathrm{L}$ ) at either 2 or 4 weeks of age. Though, one infant did not have any detectable anti-thyroid antibodies. Thyroxine treatment was discontinued for all three children permanently between year 1 and 2 of life. The findings revealed that some infants born to hypothyroid mothers tend to present with elevated TSH levels. Therefore, all such patients shall be screened to rule out the risk of hypothyroidism [15].

A multicenter prospective study Taha and Alhazmi [16] conducted in Saudi Arabia has reported that $9.3 \%$ of pregnant women were found to have overt hypothyroidism, and $14.9 \%$ were diagnosed as subclinical hypothyroidism, reflecting high prevalence rate for both disorders. There was a high rate of cesarean section for women with overt hypothyroidism as well as for women with subclinical hypothyroidism. Gestational DM developed in $23 \%$ of women with overt hypothyroidism and $34.5 \%$ with subclinical hypothyroidism. Intrauterine fetal deaths complicated $3.4 \%$ of overt hypothyroid pregnant women, a low APGAR score at delivery was encountered in $16.1 \%$ of neonates of overt hypothyroid mothers and $10.1 \%$ of neonates of subclinical hypothyroid mothers. This study 
concluded that adverse fetal and maternal outcomes and risks fetal hypothyroidism can be avoided by screening all pregnant women during first antenatal visit by simple TSH testing.

\section{Study significance}

Thyroid pathology further aggravates as pregnancy proceed. Hypothyroidism can be ongoing problem in pregnant women, or it may occur during pregnancy. However, it is often difficult to diagnose during pregnancy due to higher levels of thyroid hormones as the signs and symptoms overlap in both pregnancy and thyroid disorders. Fluctuations in thyroid hormone have a key undesirable influence on both mother as well as fetus. Therefore, it is important to monitor maternal and fetal outcomes during the pregnancy. It is also equally vital to investigate the infants of hypothyroid mothers to diagnose and rule out hypothyroidism and associated complications.

Complications associated with hypothyroidism are influenced by the severity of hypothyroidism, on how correctly and timely the therapy was begun, on other obstetrical and extragenital disease states associated with pregnancy. Effective management of maternal hypothyroidism can reduce the risk of infant hypothyroidism and other complications. Clinical symptoms are polymorphic, frequently non-specific, and are mostly associated to the time of incident and severity of thyroid hormone deficiency. The outcomes of present study will provide substantial insight to effectively manage maternal hypothyroidism and to avoid fetal hypothyroidism and associated complications. However, this study concerning hypothyroidism in pregnancy and associated maternal and fetal complications would offer significant contribution to contemporary knowledge. Thus, this study aimed to assess the prevalence of hypothyroidism in infants born to hypothyroid mothers and to analyze the maternal and fetal outcomes of pregnancy complicated by hypothyroidism.

\section{Materials and Methods}

This is a quantitative, cross-sectional study design conducted in different parts of Qassim region, Saudi Arabia by distributing research questionnaire to hypothyroid mothers. A survey designed on google docs were distributed to respondents via Email and WhatsApp as convenient for respondents. Data of pregnant women with clinical hypothyroidism during the past 5 years 2015-2019 were obtained from visiting records of endocrine clinic in Qassim University. These participants were contacted and written informed consents were obtained from after brief introduction of the study. The sample size would be consisted of 400 hypothyroid pregnant women. Sample size was calculated using the formula; $n=z^{2} p(1-p) \backslash d^{2}$ with $95 \%$ confidence level and $5 \%$ margin of error where $\mathrm{n}=$ sample size, $\mathrm{z}=1.96 \mathrm{p}=0.5, \mathrm{~d}=0.05$. To ensure accuracy, the sample size was raised to 400 to prevent any lost data or non-response.

\section{Inclusion criteria}

- $\quad$ Pregnant woman

- $\quad$ Age $>18$ years

- $\quad$ Primigravida/multigravida

- Known case of hypothyroidism on treatment

- Diagnosis given by the obstetrician and endocrinologist and the detection of the hormonal profile through lab tests.

\section{Exclusion criteria}

- $\quad$ Age $>45$ years

- $\quad$ Chronic hypertension and diabetes

- $\quad$ Complicated obstetric history

- $\quad$ Those who had undergone thyroid surgery previously

- $\quad$ Those who had been on lithium or amiodarone therapy or head and neck radiotherapy.

\section{Statistical analysis}

Descriptive statistics were presented using numbers and percentages. Complication at pregnancy was compared with the socio-demographic characteristics and children with hypothyroidism by using Fischer Exact test. $P$ value of 0.05 was considered statistically significant. The data were analyzed using Statistical Packages for Social Sciences version 26 Armonk, NY: IBM Corp.

\section{Results}

153 met the inclusion criteria. Table 1 described the socio-demographic characteristics of the mothers with hypothyroidism. The most common age group was $31-45$ years old (mean: 32.5$)$ (83\%). Saudi mothers constitute most of the participants (93.5\%). With respect to respondents' education, the majority were bachelor's or higher degrees (69.3\%). The prevalence of participants who had a family history of hypothyroidism was $71.2 \%$. Furthermore, $34 \%$ of the respondents had been diagnosed with hypothyroidism from the last 2 to 5 years. The most commonly used dose for treatment was more than $50 \mathrm{mg}$ (66\%). Likewise, $37.9 \%$ of the mothers reported having more 
Table 1: Socio-demographic characteristics of hypothyroid mothers $(n=153)$

\begin{tabular}{|c|c|}
\hline Study variables & $\mathrm{n}(\%)$ \\
\hline \multicolumn{2}{|l|}{ Age group } \\
\hline$\cdot 20-30$ years & $26(17.0 \%)$ \\
\hline$\cdot 31-45$ years & $127(83.0 \%)$ \\
\hline \multicolumn{2}{|l|}{ Nationality } \\
\hline -Saudi & $143(93.5 \%)$ \\
\hline • Non-Saudi & $10(06.5 \%)$ \\
\hline \multicolumn{2}{|l|}{ Educational level } \\
\hline • Illiterate & $01(0.70 \%)$ \\
\hline - Primary & $12(07.8 \%)$ \\
\hline - Intermediate & $09(05.9 \%)$ \\
\hline • Secondary & $25(16.3 \%)$ \\
\hline - Bachelor or higher & $106(69.3 \%)$ \\
\hline \multicolumn{2}{|c|}{ Family history of hypothyroidism } \\
\hline - Yes & 109 (71.2\%) \\
\hline • No & $44(28.8 \%)$ \\
\hline \multicolumn{2}{|c|}{ Since when were you diagnosed with hypothyroidism? } \\
\hline$\cdot<2$ years & $20(13.1 \%)$ \\
\hline - From 2 to 5 years & $52(34.0 \%)$ \\
\hline$\cdot 5-10$ years & $49(32.0 \%)$ \\
\hline$\cdot>10$ years & $32(20.9 \%)$ \\
\hline \multicolumn{2}{|c|}{ The dose used for treatment } \\
\hline$\cdot 25 \mathrm{mg}$ & $19(12.4 \%)$ \\
\hline$\cdot 50 \mathrm{mg}$ & $33(21.6 \%)$ \\
\hline • More than $50 \mathrm{mg}$ & $101(66.0 \%)$ \\
\hline \multicolumn{2}{|l|}{ Number of pregnancy } \\
\hline - Once & $23(15.0 \%)$ \\
\hline • Twice & $44(28.8 \%)$ \\
\hline - 3 times & $28(18.3 \%)$ \\
\hline - More than 3 times & $58(37.9 \%)$ \\
\hline \multicolumn{2}{|l|}{ Number of miscarriage } \\
\hline • None & $101(66.0 \%)$ \\
\hline - Once & $31(20.3 \%)$ \\
\hline • Twice & $12(07.8 \%)$ \\
\hline - 3 times & $07(04.6 \%)$ \\
\hline - More than 3 times & $02(01.3 \%)$ \\
\hline \multicolumn{2}{|l|}{ Number of children } \\
\hline - None & $42(27.5 \%)$ \\
\hline • One & $24(15.7 \%)$ \\
\hline • Two & $24(15.7 \%)$ \\
\hline • Three & $11(07.2 \%)$ \\
\hline • More than three & $52(34.0 \%)$ \\
\hline \multicolumn{2}{|c|}{ Do you follow during pregnancy? } \\
\hline - Yes & $149(97.4 \%)$ \\
\hline$\cdot$ No & $04(02.6 \%)$ \\
\hline \multicolumn{2}{|c|}{ Complication during pregnancy } \\
\hline -Yes & $72(47.1 \%)$ \\
\hline • No & $81(52.9 \%)$ \\
\hline
\end{tabular}

than 3 times of pregnancies while $20.3 \%$ reported having a single miscarriage. In addition, $34 \%$ of the mothers were having more than three children. The proportion of mothers who had regular follow-up during pregnancy was $97.4 \%$ while the prevalence of mothers who had complications during pregnancy was $47.1 \%$.

Figure 1 showed the list of complications during pregnancy. It can be observed that the most common complication during the pregnancy was C-section (26.8\%), followed by gestational DM (13.7\%) and anemia $(9.2 \%)$ while the least of them was bleeding $(1.3 \%)$.

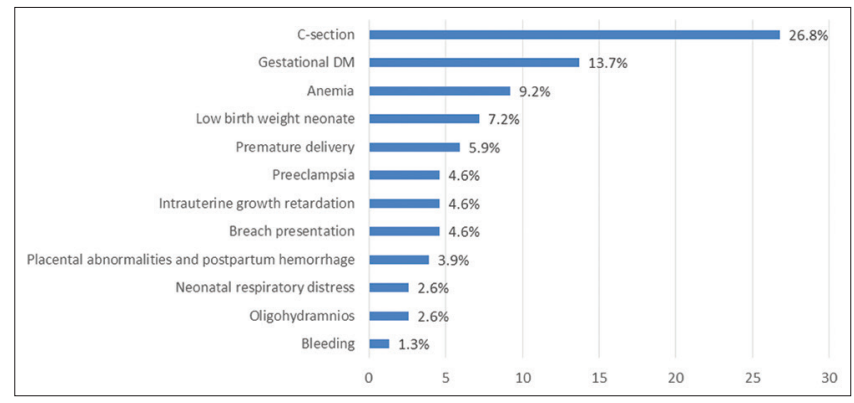

Figure 1: Complications during pregnancy

Figure 2 depicted the child's symptoms at the time of diagnosis. It was revealed that the most commonly mentioned child symptom was decreased in activity $(7.8 \%)$, followed by increased weight $(5.2 \%)$ and hair loss and dry skin $(5.2 \%)$, while short stature was the least $(0.7 \%)$.

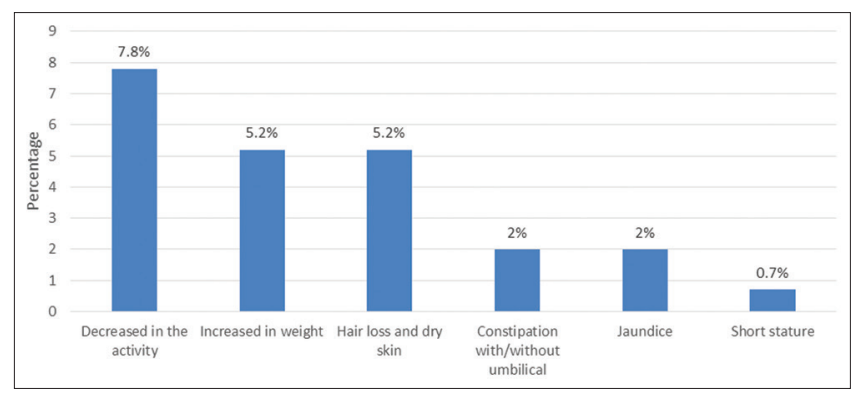

Figure 2: Child symptoms at the time of diagnosis

The prevalence and characteristics of infants who were born with hypothyroidism were given in Table 2. Following the results, it was observed that the prevalence of infants with hypothyroidism was $2.6 \%$ $(n=2)$ while the prevalence of newborns with temporary/ permanent hypothyroidism was $4.6 \%(n=7)$. Similarly, $4.6 \%$ of the mothers indicated that they have a single child with hypothyroidism with $6.5 \%$ of the hypothyroid children were aged more than 2 years. In addition, $4.6 \%$ reported having children with an autoimmune disease with type 1 diabetes was the most common of them $(28.6 \%)$.

Table 2: Prevalence and characteristics of hypothyroidism among infants and children $(n=153)$

\begin{tabular}{ll}
\hline Variables & $\mathrm{n}(\%)$ \\
\hline Are there any infants with hypothyroidism? & \\
• Yes & $04(02.6 \%)$ \\
• No & $149(97.4 \%)$ \\
Are there newborns with temporary/permanent hypothyroidism & \\
• Yes & $07(04.6 \%)$ \\
• No & $146(95.4 \%)$ \\
Number of children with hypothyroidism & \\
• None & $140(91.5 \%)$ \\
• One & $07(04.6 \%)$ \\
• Two & $04(02.6 \%)$ \\
- Three or more & $02(01.3 \%)$ \\
Age of children with hypothyroidism & \\
• None & $140(91.5 \%)$ \\
• $<6$ months & $02(01.3 \%)$ \\
- $1-2$ years & $01(0.70 \%)$ \\
• 2 years & $10(06.5 \%)$ \\
Are there children with autoimmune disease & \\
• Yes & $07(04.6 \%)$ \\
• No & $146(95.4 \%)$ \\
Type of immune disease $(\mathrm{n}=7)$ & $02(28.6 \%)$ \\
• Type 1 diabetes & $01(14.3 \%)$ \\
• Celiac disease & $04(57.1 \%)$ \\
\hline - Other diseases &
\end{tabular}

When measuring the relationship between complication at pregnancy among the selected sociodemographic characteristics of thyroid mothers, it was found that the prevalence of complication at pregnancy was more common among mothers who had an incidence of miscarriage $(p=0.004)$ and those with 1-3 children $(p=0.002)$. Other sociodemographic variables such as age group, family history of hypothyroidism, time of diagnosis, the treatment dose, number of pregnancies, infants with hypothyroidism, having newborns with temporary/ permanent hypothyroidism did not significant relationship with the complication at pregnancy $(p>0.05)($ Table 3$)$. 
Table 3: Relationship between complication at pregnancy and the socio-demographic characteristics of mothers with hypothyroidism including infant with hypothyroidism $(n=153)$

\begin{tabular}{|c|c|c|c|}
\hline \multirow[t]{2}{*}{ Factor } & \multicolumn{2}{|c|}{ Complication at pregnancy } & \multirow[t]{2}{*}{$p$-value ${ }^{5}$} \\
\hline & Yes n (\%) $(n=72)$ & No $n(\%)(n=81)$ & \\
\hline \multicolumn{4}{|l|}{ Age group } \\
\hline$\cdot 20-30$ years & $09(12.5 \%)$ & $17(21.0 \%)$ & \multirow[t]{2}{*}{0.198} \\
\hline • 31-45 years & $63(87.5 \%)$ & $64(79.0 \%)$ & \\
\hline \multicolumn{4}{|c|}{ Family history of hypothyroidism } \\
\hline - Yes & $50(69.4 \%)$ & $59(72.8 \%)$ & \multirow[t]{2}{*}{0.721} \\
\hline • No & $22(30.6 \%)$ & $22(27.2 \%)$ & \\
\hline \multicolumn{4}{|l|}{ Time of diagnosis } \\
\hline$\cdot<2$ years & $06(08.3 \%)$ & $14(17.3 \%)$ & \multirow[t]{4}{*}{0.139} \\
\hline - From 2 to 5 years & $27(37.5 \%)$ & $25(30.9 \%)$ & \\
\hline$\cdot 5-10$ years & $20(27.8 \%)$ & $29(35.8 \%)$ & \\
\hline - More than 10 years & $19(26.4 \%)$ & $13(16.0 \%)$ & \\
\hline \multicolumn{4}{|c|}{ The dose used for treatment } \\
\hline$\cdot 25 \mathrm{mg}$ & $07(09.7 \%)$ & $12(14.8 \%)$ & \multirow[t]{3}{*}{0.690} \\
\hline$\cdot 50 \mathrm{mg}$ & $16(22.2 \%)$ & $17(21.0 \%)$ & \\
\hline - More than $50 \mathrm{mg}$ & $49(68.1 \%)$ & $52(64.2 \%)$ & \\
\hline \multicolumn{4}{|l|}{ Number of pregnancy } \\
\hline • Once & $07(09.7 \%)$ & $16(19.8 \%)$ & \multirow[t]{4}{*}{0.110} \\
\hline • Twice & $19(26.4 \%)$ & $25(30.9 \%)$ & \\
\hline$\cdot 3$ times & $12(16.7 \%)$ & $16(19.8 \%)$ & \\
\hline - More than 3 times & $34(47.2 \%)$ & $24(29.6 \%)$ & \\
\hline \multicolumn{4}{|l|}{ Having Miscarriage } \\
\hline - Yes & $33(45.8 \%)$ & $19(23.5 \%)$ & \multirow[t]{2}{*}{$0.004^{\text {** }}$} \\
\hline$\cdot$ No & $39(54.2 \%)$ & $62(76.5 \%)$ & \\
\hline \multicolumn{4}{|l|}{ Number of children } \\
\hline • None & $10(13.9 \%)$ & $32(39.5 \%)$ & \multirow[t]{3}{*}{0.002 ** } \\
\hline$\cdot 1-3$ & $33(45.8 \%)$ & $26(32.1 \%)$ & \\
\hline$\cdot>3$ & $29(40.3 \%)$ & $23(28.4 \%)$ & \\
\hline \multicolumn{4}{|c|}{ Infants with hypothyroidism } \\
\hline •Yes & $03(04.2 \%)$ & $01(01.2 \%)$ & \multirow[t]{2}{*}{0.343} \\
\hline$\cdot$ No & $69(95.8 \%)$ & $80(98.8 \%)$ & \\
\hline \multicolumn{4}{|c|}{$\begin{array}{l}\text { Newborns with temporary/permanent } \\
\text { hypothyroidism }\end{array}$} \\
\hline - Yes & $03(04.2 \%)$ & $04(04.9 \%)$ & \multirow[t]{2}{*}{1.000} \\
\hline - No & $69(95.8 \%)$ & $77(95.1 \%)$ & \\
\hline
\end{tabular}

\section{Discussion}

The present study examined 153 pregnant women with clinical hypothyroidism along with pregnancy complications that have been linked to neonatal hypothyroidism. The findings of this study revealed that the 5-year prevalence of infants (year 2015-2019) with hypothyroidism was $2.6 \%(n=4)$. Furthermore, there were $4.6 \%$ of newborns with temporary or permanent hypothyroidism of which $8.5 \%$ of mothers were having one or more children with hypothyroidism. This prevalence was lower than the study reported in China [17], they investigated the incidence of $\mathrm{CH}$ from the year 2000 to 2018, based on their accounts, among 205,834 newborns screened, $189(9.2 \%)$ or $1 / 1089$ were diagnosed with $\mathrm{CH}$. They further detailed that, of those infants with $\mathrm{CH}, 46.6 \%$ were diagnosed with permanent $\mathrm{CH}$ and $53.4 \%$ were diagnosed with transient $\mathrm{CH}$. Although the prevalence of hypothyroidism was lower in our report, however, the prevalence was differed by the duration as in our study the incidence of hypothyroidism among infants was based on a 5-year duration whereas the previous reports were based on nearly two decades which could be the turning point.

Moreover, the most common symptoms of the children at the time of diagnosis was decreased activity $(7.8 \%)$, followed by an increase in weight
(5.2\%), then hair loss and dry skin $(5.2 \%)$ while short stature was estimated as the least symptoms $(0.7 \%)$. In addition, we noted $4.6 \%$ of the children detected having an autoimmune disease with type 1 diabetes was the major autoimmune disease and were detected in 2 cases.

Studies have suggested that genetics play a significant role in both determination of thyroid hormone and thyrotropin (TSH) concentrations, and susceptibility to autoimmune thyroid disease [18]. Fetal programming is a long-standing theory that bind in utero exposure with the development of disease in later life. The theory is not only related to the field of thyroid disorders [19]. In this study, a family history of hypothyroidism was accounted for $71.2 \%$. Likewise, $34 \%$ of the respondents had been diagnosed with the disease since $2-5$ years ago, others were $5-10$ years ago (32\%). The genetic influence of hypothyroidism had been well-documented in publications. For example, a study done by Zhou et al. [17], reported that women who had subclincal hypothyroidism or diabetes during pregnancy had an increased risk of having offspring with $\mathrm{CH}$. This had been corroborated by the study of Grattan et al. [20], based on their investigations, mothers with a history of hypothyroidism were significantly more likely to have offspring with $\mathrm{CH}$ compared to those without having a history.

Incidentally, $47.1 \%$ of the mothers experienced complications during pregnancy with those who experienced complications, $40.3 \%$ had multiple complications and the rest had a single one. This is consistent with the report of Vinodhini et al. [9] According to their results, the incidence of complication was identified among $41 \%$ in the subclinical hypothyroid mothers and $78 \%$ in the overt hypothyroid group. Conversely, the most commonly detected complication during pregnancy was cesarean delivery $(26.8 \%)$, followed by gestational DM $(13.7 \%)$, and anemia (9.2\%). Other reported complications were as follows; low birth weight $(7.2 \%)$, premature delivery $(5.9 \%)$, preeclampsia $(4.6 \%)$, intrauterine growth retardation $(4.6 \%)$, breech presentation $(4.6 \%)$, placental abnormalities, and postpartum hemorrhage $(3.9 \%)$, neonatal respiratory distress $(2.6 \%)$, Oligohydramnios $(2.6 \%)$, and bleeding $(1.3 \%)$. In a study done by Männistö et al. [11], they documented that hypothyroidism was associated with increased odds of preeclampsia, superimposed preeclampsia, gestational DM, preterm birth, induction, cesarean section, and ICU admission which was comparable with our results. In Romania [21], fetal suffering, respiratory distress, and postpartum hemorrhage were identified as the most dominant pregnancy complication of hypothyroid mothers while in the USA [22], meconium (22.6\%), operative vaginal delivery $(20.6 \%)$ and cesarean delivery $(15.8 \%)$ were some of the complications being identified, however, they concluded that treated hypothyroidism was not 
associated with an increased risk in maternal, fetal, or neonatal complications and it did not affect the mode of delivery.

Accordingly, we noticed that hypothyroid mothers who had incidence of miscarriage and of whom were having 1 to 3 children had increased risk of complication during pregnancy while on the other hand, this did not seem to affect among neonates with temporary/permanent hypothyroidism. These findings are almost in agreement with the study of Tina et al. [22] Based on their reports, it was revealed that treated hypothyroidism was not associated with any increase in maternal, fetal, or neonatal complications and it did not affect mode of delivery.

\section{Conclusion}

Infants with hypothyroidism were not widely prevalent in this study. Cesarean delivery, gestational diabetes, and anemia were some of the most common maternal complications during pregnancy. Early detection, immediate treatment, and constant monitoring toward the administration of the appropriate dose would have a significant role in preventing the incidence of maternal and fetal complications. Further research is needed to shed more light regarding maternal complications and their effect on their newborn baby.

\section{References}

1. Stricker R, Echenard M, Eberhart R, Chevailler M, Perez V, Quinn $\mathrm{F}$, et al. Evaluation of maternal thyroid function during pregnancy: The importance of using gestational age-specific reference intervals. Eur J Endocrinol. 2007;157(4):509-14. http://doi.org/10.1530/EJE-07-0249

PMid:17893266

2. Elahi S, Hussain Z. A longitudinal study of changes in thyroid related hormones among pregnant women residing in an iodine deficient urban area. ISRN Endocrinol. 2013;2013:234031. http://doi.org/10.1155/2013/234031

PMid:24236234

3. Cignini $P$, Cafà EV, Giorlandino C, Capriglione S, Spata A, Dugo N. Thyroid physiology and common diseases in pregnancy: Review of literature. J Prenat Med. 2012;6(4):64-71. PMid:23272277

4. Talat A, Khan AA, Nasreen S, Wass JA. Thyroid screening during early pregnancy and the need for trimester specific reference ranges: A cross-sectional study in Lahore, Pakistan. Cureus. 2019;11(9):e5661. http://doi.org/10.7759/cureus.5661 PMid:31720137

5. Stagnaro-Green A, Abalovich M, Alexander E, Azizi F, Mestman J, Negro R, et al. Guidelines of the American thyroid association for the diagnosis and management of thyroid disease during pregnancy and postpartum. Thyroid. 2011;21(10):1081125. http://doi.org/10.1089/thy.2011.0087

PMid:21787128

6. Teng W, Shan Z, Patil-Sisodia K, Cooper DS. Hypothyroidism in pregnancy. Lancet Diabetes Endocrinol. 2013;1(3):228-37. http://doi.org/10.1016/S2213-8587(13)70109-8 PMid:24622371

7. De Groot L, Abalovich M, Alexander EK, Amino N, Barbour L, Cobin $\mathrm{RH}$, et al. Management of thyroid dysfunction during pregnancy and postpartum: An endocrine society clinical practice guideline. J Clin Endocrinol Metab. 2012;97(8):2543-65. http:// doi.org/10.1210/jc.2011-2803

PMid:22869843

8. Aboelroose AA. Assessment of thyroid function in pregnant women attending Suez Canal University Hospitals. Int J Pregnancy Child Birth. 2019;5(5):65-9.

9. Vinodhini S. An Analytical Cross Sectional study on Hypothyroidism in Pregnancy, Its Maternal and Fetal Outcome: Kilpauk Medical College, Chennai; 2019.

10. Gupta M, Pandotra P, Jindal M, Jamwal G, Goraya S, Gupta V. Comparative study of feto-maternal outcome in clinical and subclinical hypothyroidism. Int J Reprod Contracept Obstet Gynecol. 2017;6(5):1910.

11. Männistö T, Mendola P, Grewal J, Xie Y, Chen Z, Laughon SK Thyroid diseases and adverse pregnancy outcomes in a contemporary US cohort. J Clin Endocrinol Metab. 2013;98(7):2725-33. http://doi.org/10.1210/jc.2012-4233 PMid:23744409

12. Fallatah $\mathrm{AM}$, Hasanain $\mathrm{A}$, Babatin $\mathrm{H}$, Nassibi KM, Thigah $\mathrm{S}$ Abduljabbar HS. Pregnancy outcomes among obese pregnant women with hypothyroidism: Medical record review of a single tertiary center in Saudi Arabia. Cureus. 2020;12(2):e6938. http://doi.org/10.7759/cureus.6938

PMid:32190490

13. Al Shanqeeti SA, Alkhudairy YN, Alabdulwahed AA, Ahmed AE, Al-Adham MS, Mahmood NM. Prevalence of subclinical hypothyroidism in pregnancy in Saudi Arabia. Saudi Med J. 2018;39(3):254. http://doi.org/10.15537/smj.2018.3.21621 PMid:29543303

14. Hussein KS. Prevalence of thyroid dysfunction among Saud women in early pregnancy at King Abdulaziz University Hospital. World J Environ Biosci. 2017;6:21-5.

15. Rovelli R, Vigone MC, Giovanettoni C, Passoni A, Maina L, Corrias A, et al. Newborn of mothers affected by autoimmune thyroiditis: The importance of thyroid function monitoring in the first months of life. Ital J Pediatr. 2010;36(1):24. http://doi. org/10.1186/1824-7288-36-24 PMid:20219125

16. Taha I, Alhazmi J, editors. Prevalence of Overt and Subclinical Hypothyroidism among Saudi Pregnant Women Attending Two Referral Hospitals in Saudi Arabia and Associated Maternal and Fetal Complications. Society for Endocrinology BES; 2011.

17. Zhou J, Luo J, Lin J, Zeng Y, Qiu X, Zhu W, et al. Perinata risk factors for congenital hypothyroidism: A retrospective cohort study performed at a tertiary hospital in China. Medicine. 2020;99(26):e20838. http://doi.org/10.1097/ MD. 0000000000020838 PMid:32590776

18. Panicker V. Genetics of thyroid function and disease. Clin Biochem Rev. 2011;32(4):165-75.

PMid:22147956

19. Andersen SL, Andersen S. Turning to thyroid disease in pregnant women. Eur Thyroid J. 2020;9:225-33.

20. Grattan MJ, Thomas DS, Hornberger LK, Hamilton RM, MidodziWK, VohraS. Maternal hypothyroidism may beassociated 
with CHD in offspring. Cardiol Young. 2015;25(7):1247-53. http://doi.org/10.1017/S1047951114001887

PMid:25275697

21. Tudosa R, Vartej P, Horhoianu I, Ghica C, Mateescu S, Dumitrache I. Maternal and fetal complications of the hypothyroidism-related pregnancy. Maedica. 2010;5(2):116. PMid:21977134

22. Tan TO, Cheng YW, Caughey AB. Are women who are treated for hypothyroidism at risk for pregnancy complications? Am J Obstet Gynecol. 2006;194(5):e1-3. 